\title{
Prevalence of schistosomiasis and associated risk factors among school children in Um-Asher Area, Khartoum, Sudan
}

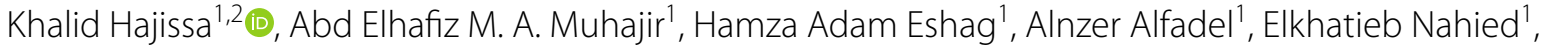 \\ Rabeea Dahab', Safa Mohammed Ali ${ }^{1}$, Marwa Mohammed ${ }^{1}$, Mohamed Gaafar ${ }^{3}$ and Zeehaida Mohamed²
}

\begin{abstract}
Objective: Schistosomiasis remains one of the most common parasitic diseases worldwide. This is a cross-sectional study aimed to determine the prevalence of schistosomiasis and its associated risk factors among primary school children in Um-Asher area. The study was conducted among 170 primary school students in Um-Asher area from November 2017 to February 2018. Urine and stool samples were collected and examined for schistosomiasis infections. Moreover, data on sociodemographic characteristics and associated risk factors were obtained using a questionnaire.

Results: The overall prevalence of Schistosoma haematobium was 12.9\%, whereas that of Schistosoma mansoni was $2.95 \%$. Additionally, the males had higher prevalence (60\%) of S. mansoni than females (40\%). However, both gender were equally infected with S. haematobium (50\%). With regard to risk factors, distance of residence from water source and source of drinking water are relatively associated with the infection.
\end{abstract}

Keywords: Schistosoma haematobium, Schistosoma mansoni, School children, Sudan

\section{Introduction}

Schistosomiasis is one of the most commonly neglected tropical diseases associated with significant morbidity and mortality in many developing countries in tropical and subtropical regions of Africa, Latin America and Asia [1]. Schistosomiasis remains a major health problem with significant socioeconomic impact in areas where control efforts and sanitation are inadequate and the majority of populations are impoverished [2]. The global prevalence of schistosomiasis is relatively high especially in developing countries. Recent estimates indicate that 779 million people are at the risk of infection, and $85 \%$ of them are in Africa. Approximately 207 million individuals in 74 countries are infected with schistosomiasis, and 120 million of these people developed the disease [3, 4]. Thirtyone African countries including Sudan have the great

\footnotetext{
*Correspondence: zeehaida@usm.my

2 Department of Medical Microbiology \& Parasitology, School of Medical

Sciences, Universiti Sains Malaysia, 16150 Kubang Kerian, Kelantan,

Malaysia

Full list of author information is available at the end of the article
}

burden of this disease, and millions of individuals have been suffering from schistosomiasis [3]. Africa houses at least $90 \%$ of infected people requiring schistosomiasis treatment [5].

In Sudan, this disease is predominantly caused by two species, namely, Schistosoma haematobium (S. haematobium), which cause urinary schistosomiasis, and Schistosoma mansoni (S. mansoni), which is responsible for intestinal schistosomiasis [6]. Schistosomiasis is often associated with many factors which correlate significantly with the spread of diseases in different regions of the country. These factors include low socioeconomic status, lack of clean water supply, lack of basic infrastructure, relatively low quality of housing and poor environmental sanitation.

Schistosomiasis endemicity was first reported in Sudan in 1904 by Balfour, who investigated the presence of urinary schistosomiasis among children in Khartoum Primary School. Among these individuals, 17\% were positive despite the long-time existence of the disease in this country [7-10]. Various epidemiological studies 
showed that infections with S. haematobium and S. mansoni are widely distributed in different regions of Sudan. Since 1919, the disease has been first reported in northern Sudan and has been prevalent in different parts of the country including Darfur (western Sudan) [11, 12], White Nile State [9] and Southern Kordofan State [13]. The disease is also endemic in different villagers of Gezira agricultural scheme [4, 14] and New Halfa agricultural scheme [10].

In developing countries, children aged 5-17 years possess the highest risk of infection and are the most infected group [15]. Personal hygiene and high frequency of contact with water in an endemic area might significantly increase the risk of acquiring this infection [3]. In addition, poor sanitation, bathing and swimming in dams and rivers or crossing rivers on the way to school barefooted, type and consistent use of toilet, uses of unprotected water sources to watering the vegetable gardens and knowledge about schistosomiasis are the risks that significantly associated with higher rates of infection [16]. The adverse effects of schistosomiasis among this group are diverse and alarming, the infection can lead to urethral and bladder fibrosis and hydronephrosis, hepatosplenomegaly, moreover, bladder cancer and colorectal cancer is a possible late-stage complication $[17,18]$. Thus, this study was conducted to determine the prevalence of schistosomiasis and the associated risk factors among school age children from Um-Asher area, South Khartoum, Sudan.

\section{Main text \\ Methodology \\ Study area}

The study was conducted in Um-Asher (Al Kalakla) area located at $15^{\circ} 28^{\prime} 04^{\prime \prime}$ North, $32^{\circ} 29^{\prime} 08^{\prime \prime}$ East with a height of $384 \mathrm{~m}$ and $16.3 \mathrm{~km}$ south of Khartoum, Sudan.

\section{Study design, period and participants}

This was a cross-sectional study conducted from November 2017 until June 2018. Study participants were randomly selected from two primary schools at the study area. In these two schools, 170 children (75 males and 95 were females) were voluntary enrolled.

\section{Inclusion and exclusion criteria}

Children aged between 6 and 17 years attending the selected schools during the study period were enrolled. Meanwhile, all children who were seriously ill or took medication for schistosomiasis in the period of 3 weeks from the time of data collection were excluded.

\section{Sample collection}

All the study participants were requested to provide both urine and stool samples by using dry, clean well-labelled plastic containers. Approximately 5-10 $\mathrm{ml}$ of urine and 5-7 g of faeces were collected. Consequently, $10 \%$ formaldehyde was added to the stool sample as preservative, whereas no preservative material was added to the urine samples. In addition, the sociodemographic and associated risk factors were obtained via a standardized questionnaire. All samples were then transferred to the laboratory of Zoology Department for further examinations.

\section{Microscopic examination}

Urine samples were microscopically examined for the presence of $S$. haematobium eggs by using simple centrifugation/sedimentation [10]. The microscopic diagnosis of $S$. mansoni infection in faecal samples was performed using direct stool examination method [19]. All microscopic slides containing the eggs of S. haematobium or $S$. mansoni were considered positive, whereas the absence of the eggs was recorded as negative.

\section{Statistical analysis}

Data obtained from this study were entered into Statistical Package for Social Sciences (SPSS) version 23 and analysed using Chi square to determine the correlation between variables and risk factors. $P$ value less than .05 was considered significant.

\section{Results}

A total of 170 participants aged between 6 and 17 years from two selected primary schools in Um-Asher area were enrolled in this study. Among the participants, 95 (55.9\%) were females, and 75 (44.1\%) were males. Based on the age group, the majority of study participants were aged between 10 and 13 years (106 participants), whereas those aged 6-9 and 14-17 years comprised 38 and 16 of each group, respectively.

The prevalence rates of $S$. haematobium was $12.9 \%$ $(22 / 170)$. The analysis indicated that males and females were equally infected ( $50 \%$ each). With regards to age, children aged between 10 and 13 years were the most infected with an infection rate of $81.8 \%$ compared with the other age groups. Participants who had non-sanitary latrine had higher risk for acquiring the infection (Table 1).

The prevalence rates of S. mansoni were $2.9 \%$ (5/170), the infection is higher in males (60\%) than in females (40\%) although the difference is not statistically significant. All the infection occurred among young children 
Table 1 Risk factors associated with S. haematobium infection $(n=170)$

\begin{tabular}{|c|c|c|c|c|}
\hline \multirow[t]{2}{*}{ Variable } & \multicolumn{2}{|c|}{ Infection, $\mathrm{n}(\%)$} & \multirow[t]{2}{*}{$X^{2}(d f)$} & \multirow[t]{2}{*}{$P$ value } \\
\hline & Positive & Negative & & \\
\hline \multicolumn{5}{|l|}{ Gender } \\
\hline Male & $11(50 \%)$ & $64(43.2 \%)$ & $.355(1)$ & .551 \\
\hline Female & $11(50 \%)$ & $84(56.8 \%)$ & & \\
\hline \multicolumn{5}{|l|}{ Age } \\
\hline $6-9$ & $1(4.5 \%)$ & $37(25 \%)$ & $4.747(2)$ & .093 \\
\hline $10-13$ & $18(81.8 \%)$ & $98(66.2 \%)$ & & \\
\hline $14-17$ & $3(13.6 \%)$ & $13(8.8 \%)$ & & \\
\hline \multicolumn{5}{|c|}{ Distance of residence from water source } \\
\hline Far & $15(68.2 \%)$ & $98(66.2 \%)$ & $.33(1)$ & .855 \\
\hline Near & $7(31.8 \%)$ & $50(33.8 \%)$ & & \\
\hline \multicolumn{5}{|l|}{ Type of toilet } \\
\hline Sanitary latrine & $8(36.4 \%)$ & $57(38.5 \%)$ & $.037(1)$ & .846 \\
\hline Non-sanitary latrine & $14(63.6 \%)$ & $91(61.5 \%)$ & & \\
\hline \multicolumn{5}{|l|}{ Bathing habit } \\
\hline Home & $22(100 \%)$ & $129(87.2 \%)$ & $3.180(3)$ & .365 \\
\hline Canal & $0(.0 \%)$ & $3(2.0 \%)$ & & \\
\hline River & $0(.0 \%)$ & $3(2.0 \%)$ & & \\
\hline All & $0(.0 \%)$ & $13(8.8 \%)$ & & \\
\hline \multicolumn{5}{|c|}{ Parents educational status } \\
\hline Primary & $8(36.4 \%)$ & $39(26.4 \%)$ & $1.107(3)$ & .775 \\
\hline Inter mediate & $3(13.6 \%)$ & $21(14.2 \%)$ & & \\
\hline Secondary & $4(18.2 \%)$ & $37(25 \%)$ & & \\
\hline University & $7(31.8 \%)$ & $51(34.5 \%)$ & & \\
\hline
\end{tabular}

up to aged 13 years old. There was no significant associated risk factors found for Schistosoma mansoni infection (Table 2).

\section{Discussion}

Schistosomiasis remains a public health concern in various developing countries including Sudan. School age children are among the high risk groups for $S$. haematobium and S. mansoni infections. The present study revealed that the prevalence of $S$. haematobium among the study participants was $12.9 \%$, which was extremely lower comparing with $45.0 \%-56.0 \%$ reported from different parts of Sudan $[6,18]$. However, slightly high prevalence was also reported in Gezira area, Central Sudan (20.0\%) [4] and Southern Kordofan State (23.7\%) [13]. In general, the high prevalence of S. haematobium reported among the other studies rather than this study might be due to the reason that children in developing countries including Sudan live in poor sanitation areas, and most of them often spend long time bathing or swimming in contaminated water. Additionally, hygiene and playing behaviour in contaminated water could also increase the risk of infection. However, the low infection rate reported from this study might be attributed to the small sample size variations or the mass treatment with praziquantel which established in the last few years in the study area.

In contrast to our results, high prevalence of S. haematobium among school age children were reported from other similar studies conducted in Ethiopia [20] and Senegal [21], wherein the prevalence rates were $20.8 \%$ and $57.6 \%$, respectively $[20,21]$. However, our finding was higher than that of the previous investigation conducted in southern Mauritania (4.0\%) [5]. Additionally, an infection rate of $10.4 \%$ of $S$. haematobium among primary school children was reported in Malawi [22]. The variation in the infection rate among those areas could be due to the target population, environmental condition of the area, sample size variations and the life and behaviour of the children.

Despite the varying prevalence of $S$. haematobium between gender due to the behaviour difference that affected the rate of contact with contaminated water in most studies, unlikely, no differences were observed in the prevalence of $S$. haematobium among males and females [20]. However, males were usually more infected than females [10], and this finding could be due to the diverse outdoor activities of males exposed to cercariainfected water. Even though, some studies indicated that the prevalence among females was higher than that among males [23]. Meanwhile, the percentage of infected children in the 10-13 year group was higher than that in the 6-9 and 14-17 year groups. This finding was similarly reported in previous studies $[6,21,24]$ and might be explained by frequent contact to the river (swimming/ playing) due to excessive mobility of children at this age.

On the other hand, the prevalence of $S$. mansoni was $2.9 \%$, which is similar to that in other studies conducted previously in Sudan [18]. However, high prevalence of $51.5 \%$ of the disease was also recorded in the upper Nile region [25]. Globally, the prevalence was significantly lower than that reported in various studies conducted in Senegal (57.6\%) [21], Southern Ethiopia (81.3\%) [26], Congo 26.5\% [27], 22.9\% and 20.2\% in Brazil [28]. With regard to gender, 3 out of 5 (2.9\%) S. mansoni-infected children were males $(60 \%)$ and $2(40 \%)$ were females. This percentage is less than that reported from South Eastern Ethiopia (12.6) \% [19] and the 70.9\% reported from southern Kordofan [13]. The study also stated that children who live near water resources represent $60 \%$ of the infected student compared with the $40 \%$ living far from water resources. This finding might be due to the high chance of those living near the water source and playing in the water. Therefore, the results of this study emphasize the need of conducting other studies with large sample size and snail survey to assess the role of 
Table 2 Risk factors associated with S. mansoni infection $(\mathrm{n}=\mathbf{1 7 0})$

\begin{tabular}{|c|c|c|c|c|}
\hline \multirow[t]{2}{*}{ Variable } & \multicolumn{2}{|c|}{ Infection, $\mathrm{n}(\%)$} & \multirow[t]{2}{*}{$\mathrm{X}^{2}(d f)$} & \multirow[t]{2}{*}{$P$ value } \\
\hline & Positive & Negative & & \\
\hline \multicolumn{5}{|l|}{ Gender } \\
\hline Male & $3(60 \%)$ & $72(43.6 \%)$ & $.527(1)$ & .468 \\
\hline Female & $2(40 \%)$ & $93(56.4 \%)$ & & \\
\hline \multicolumn{5}{|l|}{ Age } \\
\hline $6-9$ & $2(40 \%)$ & $36(21.8 \%)$ & $1.254(2)$ & .534 \\
\hline $10-13$ & $3(60 \%)$ & $113(68.5 \%)$ & & \\
\hline $14-17$ & $0(.0 \%)$ & $16(9.7 \%)$ & & \\
\hline \multicolumn{5}{|c|}{ Distance of residence from water source } \\
\hline Far & $3(60 \%)$ & $110(66.7 \%)$ & $.097(1)$ & .756 \\
\hline Near & $2(40 \%)$ & $55(33.3 \%)$ & & \\
\hline \multicolumn{5}{|l|}{ Type of toilet } \\
\hline Sanitary latrine & $4(80 \%)$ & $61(37 \%)$ & $3.805(1)$ & .051 \\
\hline Non-sanitary latrine & $1(20 \%)$ & $104(63 \%)$ & & \\
\hline \multicolumn{5}{|c|}{ Habit of washing clothes } \\
\hline Home & $5(100 \%)$ & $160(97 \%)$ & $.156(2)$ & .925 \\
\hline River and canal & $0(.0 \%)$ & $2(1.2 \%)$ & & \\
\hline Other & $0(.0 \%)$ & $3(1.8 \%)$ & & \\
\hline \multicolumn{5}{|l|}{ Bathing habit } \\
\hline Home & $5(100 \%)$ & $146(88.5 \%)$ & $.648(3)$ & .885 \\
\hline Canal & $0(.0 \%)$ & $3(1.8 \%)$ & & \\
\hline River & $0(.0 \%)$ & $3(1.8 \%)$ & & \\
\hline All & $0(.0 \%)$ & $13(7.9 \%)$ & & \\
\hline \multicolumn{5}{|c|}{ Parents educational status } \\
\hline Primary & $3(60 \%)$ & $44(26.7 \%)$ & $3.015(3)$ & .389 \\
\hline Inter mediate & $0(.0 \%)$ & $24(14.5 \%)$ & & \\
\hline Secondary & $1(20 \%)$ & $40(34.5 \%)$ & & \\
\hline University & $1(20 \%)$ & $57(34.5 \%)$ & & \\
\hline
\end{tabular}

water sources in disease transmission and the implementation of effective control program to decrease the prevalence of schistosomiasis in the study area.

This study indicated the slightly high prevalence of $S$. haematobium infection and the extremely low prevalence of $S$. mansoni infection. Therefore, appropriate integrated control program and prevention measures must be implemented in the study area.

\section{Limitations}

The study was limited by the small sample size even though it provides a preliminary data about the prevalence of schistosomiasis among school children in UmAsher Area, however, the study still ongoing to enrol more children and schools in the area.
Authors' contributions

$\mathrm{KH}, \mathrm{AEM}, \mathrm{MG}$ and $\mathrm{ZM}$ : conceived and designed the study, $\mathrm{HAE}, \mathrm{AA}, \mathrm{EN}, \mathrm{RD}$, SMA and MM: field and laboratory work and data analysis. All authors read and approved the final manuscript.

\section{Author details}

1 Department of Zoology, Faculty of Science and Technology, Omdurman Islamic University, B.O.Box382, Omdurman, Sudan. ${ }^{2}$ Department of Medical Microbiology \& Parasitology, School of Medical Sciences, Universiti Sains Malaysia, 16150 Kubang Kerian, Kelantan, Malaysia. ${ }^{3}$ Weaad Medical Center, Khartoum, Sudan.

\section{Acknowledgements}

The authors would like to thank school's directors and all study participants for their contribution in success of this work.

\section{Competing interests}

The authors declare that they have no competing interests.

Availability of data and materials

All original or analyzed data for this study is available on request from the corresponding author.

\section{Consent for publication}

Not applicable.

\section{Ethics approval and consent to participate}

The study was conducted after approval of the project by ethical review committee of the Research directorate, Federal Ministry of Health (fmoh/nhrc/rd/ rec). Verbal consent was taken from the head of target schools, while the children were involved in the study after informed written consent was obtained from the parents or guardians and assent from all participating children.

\section{Funding}

This study was supported by the Grants of the Commission of Scientific Research and Innovation, Ministry of Higher Education and Scientific Research, Sudan, Grant No. SRIC/2017/RP761. Funding commission had no input in study design, conception, and the conduct of the study.

\section{Publisher's Note}

Springer Nature remains neutral with regard to jurisdictional claims in published maps and institutional affiliations.

Received: 4 October 2018 Accepted: 21 October 2018

Published online: 31 October 2018

References

1. Odhiambo GO, Musuva RM, Atuncha VO, Mutete ET, Odiere MR, Onyango $\mathrm{RO}$, et al. Low levels of awareness despite high prevalence of schistosomiasis among communities in Nyalenda informal settlement, Kisumu City, Western Kenya. PLoS Negl Trop Dis. 2014;8(4):e2784.

2. Sady H, Al-Mekhlafi HM, Mahdy MA, Lim YA, Mahmud R, Surin J. Prevalence and associated factors of schistosomiasis among children in Yemen: implications for an effective control programme. PLoS Negl Trop Dis. 2013;7(8):e2377.

3. Bajiro M, Dana D, Ayana M, Emana D, Mekonnen Z, Zawdie B, et al. Prevalence of Schistosoma mansoni infection and the therapeutic efficacy of praziquantel among school children in Manna District, Jimma Zone, southwest Ethiopia. Parasit Vectors. 2016;9(1):560.

4. Eltayeb NM, Mukhtar MM, Mohamed AB. Epidemiology of schistosomiasis in Gezira area Central Sudan and analysis of cytokine profiles. Asian Pac J Trop Med. 2013:6(2):119-25.

5. N'Guessan G, Silué KD, Ba O, Ba H, Tian-Bi NT, Yapi GY, et al. Prevalence and seasonal transmission of Schistosoma haematobium infection among school-aged children in Kaedi town, southern Mauritania. Parasit Vectors. 2017;10(1):353. 
6. Deribe K, Eldaw A, Hadziabduli S, Kailie E, Omer MD, Mohammed AE, et al. High prevalence of urinary schistosomiasis in two communities in South Darfur: implication for interventions. Parasit Vectors. 2011;4(1):14.

7. Doumenge J-P, Mott KE, Cheung C. Atlas of the global distribution of schistosomiasis continued: Presses Universitaires de Bordeaux; 1987

8. Balfour A. Second report of the wellcome research laboratories at the Gordon Memorial College. Khartoum: Department of Education, Sudan Government; 1906.

9. Hassan SAM, Abdelkreem E. Detection rate of urinary schistosomiasis in El khiar Villages White Nile State, Sudan. Pyrex J Biomed Res. 2017;3(5):34-8.

10. Afifi A, Ahmed A, Sulieman Y, Pengsakul T. Epidemiology of schistosomiasis among villagers of the New Halfa Agricultural Scheme, Sudan. Iran J Parasitol. 2016;11(1):110.

11. Ahmed A, Afifi A, Adam I. High prevalence of Schistosoma haematobium infection in Gereida Camp, in southern Darfur, Sudan. Ann Trop Med Parasitol. 2009;103(8):741-3.

12. Zakaria A. Epidemiological observations of intestinal schistosomiasis in Jebel Marra area, Darfur State, Sudan: M. Sc. thesis, Department of Zoology, Faculty of Science, University of Khartoum; 2002.

13. Abou-Zeid AH, Abkar TA, Mohamed RO. Schistosomiasis infection among primary school students in a war zone, Southern Kordofan State, Sudan: a cross-sectional study. BMC Public Health. 2013;13(1):643.

14. Bella H, Marshall TC, Omer A, Vaughan J. Migrant workers and schistosomiasis in the Gezira, Sudan. Trans R Soc Trop Med Hyg. 1980;74(1):36-9.

15. Maru DS. Prevalence of intestinal parasitic infections and associated risk factors among school children in Adigrat town, Northern Ethiopia. Int J Emerg Trends Sci Technol. 2015:4(1):4943-8.

16. Nyati-Jokomo Z, Chimbari MJ. Risk factors for schistosomiasis transmission among school children in Gwanda district, Zimbabwe. Acta Trop. 2017;175:84-90

17. Herman AM, Kishe A, Babu H, Shilanaiman H, Tarmohamed M, Lodhia J, et al. Colorectal cancer in a patient with intestinal schistosomiasis: a case report from Kilimanjaro Christian Medical Center Northern Zone Tanzania. World J Surg Oncol. 2017;15(1):146.

18. Ismail HAHA, Hong S-T, Babiker ATEB, Hassan RMAE, Sulaiman MAZ, Jeong $\mathrm{H}-\mathrm{G}$, et al. Prevalence, risk factors, and clinical manifestations of schistosomiasis among school children in the White Nile River basin, Sudan. Parasit Vectors. 2014;7(1):478
19. Tulu B, Taye S, Amsalu E. Prevalence and its associated risk factors of intestinal parasitic infections among Yadot primary school children of South Eastern Ethiopia: a cross-sectional study. BMC Res Notes. 2014;7(1):848.

20. Degarege A, Mekonnen Z, Levecke B, Legesse M, Negash Y, Vercruysse $J$, et al. Prevalence of Schistosoma haematobium infection among school-age children in afar area, Northeastern Ethiopia. PLoS ONE. 2015;10(8):e0133142.

21. Senghor B, Diallo A, Sylla SN, Doucouré S, Ndiath MO, Gaayeb L, et al. Prevalence and intensity of urinary schistosomiasis among school children in the district of Niakhar, region of Fatick, Senegal. Parasit Vectors. 2014;7(1):5.

22. Kapito-Tembo AP, Mwapasa V, Meshnick SR, Samanyika Y, Banda D, Bowie $C$, et al. Prevalence distribution and risk factors for Schistosoma hematobium infection among school children in Blantyre, Malawi. PLoS Negl Trop Dis. 2009;3(1):e361.

23. Ekpo UF, Laja-Deile A, Oluwole AS, Sam-Wobo SO, Mafiana CF. Urinary schistosomiasis among preschool children in a rural community near Abeokuta, Nigeria. Parasit Vectors. 2010;3(1):58.

24. Ugbomoiko U, Ofoezie I, Okoye I, Heukelbach J. Factors associated with urinary schistosomiasis in two peri-urban communities in south-western Nigeria. Ann Trop Med Parasitol. 2010;104(5):409-19.

25. Deganello R, Cruciani M, Beltramello C, Duncan O, Oyugi V, Montresor A. Schistosoma hematobium and S. mansoni among children, Southern Sudan. Emerg Infect Dis. 2007;13(10):1504.

26. Alemayehu B, Tomass Z. Schistosoma mansoni infection prevalence and associated risk factors among schoolchildren in Demba Girara, Damot Woide District of Wolaita Zone, Southern Ethiopia. Asian Pac J Trop Med. 2015;8(6):457-63.

27. Khonde Kumbu R, Mbanzulu Makola K, Bin L. Prevalence of Schistosoma mansoni infection in four health areas of Kisantu health zone, Democratic Republic of the Congo. Adv Med. 2016:2016:6596095.

28. Conceição MJ, Carlôto AE, de Melo EV, da Silva IM, Coura JR. Prevalence and Morbidity Data on Schistosoma mansoni infection in two rural areas of Jequitinhonha and Rio Doce Valleys in Minas Gerais, Brazil. ISRN Parasitol. 2013;2013:715195.
Ready to submit your research? Choose BMC and benefit from:

- fast, convenient online submission

- thorough peer review by experienced researchers in your field

- rapid publication on acceptance

- support for research data, including large and complex data types

- gold Open Access which fosters wider collaboration and increased citations

- maximum visibility for your research: over $100 \mathrm{M}$ website views per year

At $\mathrm{BMC}$, research is always in progress.

Learn more biomedcentral.com/submissions 